rendered unnecessary the establishment of special convalescent hospitals ; but the function of the one class will not be interfered with by the existence of the other; abundant claimants will ever appear for all the accommodation which these, in their separate departments, can afford. Of the former class, we have for some time had a temporary hospital open, which will now be transferred to a larger and more extensive establishment recently completed. This has been erected within a short distance of the town, in a very healthy locality, at the sole expense of one of our distinguished fellow-townsmen, and by him dedicated to public use. It is constructed to accommodate one hundred convalescents, and is supplied, so far as I can understand, with every necessary appliance. The honest hospital patient desires as speedy a return as possible to his remunerative toil; and many, no doubt, are tempted, under the pressure of family necessities, too soon to make the effort. Before the sequelæ of disease are thoroughly eradicated, or the consequent debility entirely recovered from, over-exertion favours relapse, or prevents the complete restoration of physical power. It may be that the premature return to the badly ventilated workshop, where our artizan patient endeavours to provide for the wants of those depending upon him for daily sustenance, or to the deteriorated atmosphere of his confined dwelling, in which he vainly seeks the renovation of his exhausted powers, tends to rekindle the scarcely extinguished embers of disease.

To all these evils the Convalescent Hospital or the Watering-place Infirmary affords an efficient and ready remedy; and, when fairly and honestly adopted, it yields to the community, whether giver or receiver, an unmixed good. But we must not shut our eyes to the fact that we have another and very different class of our hospital population to deal with. All charitable institutions are liable to abuse, and none of these so much or so detrimentally, in my opinion, as the convalescent hospital proper. Care must be taken that the malingerer does not establish his residence; and with equal vigilance the incurable must be excluded. These, if allowed facile admission, will completely destroy the usefulness which these very valuable institutions are capable of exercising, and convert into a crying abuse the otherwise beneficent agency of these adjuvant asylums.

Wherever convalescent establishments are erected for their special purposes, they should be constructed on a plan as little resembling the regular hospital as possible. The reasons warranting this are obvious. I cannot, however, endorse the directions of Miss Nightingale that, in convalescent hospitals, the requisites for ventilation, and to a very large extent the abundant space established as necessary in regular hospital construction, should be, or may be, disregarded. I do not assert that the same cubic space and superficial area are equally needful for the convalescent as for the invalid ; but a large difference cannot, in my opinion, be safely made. If small wards in hospitals are objectionable on the ground of difficulty of ventilation, and if curtains are likewise undesirable for the same reason, I see no excuse for their adoption in convalescent hospitals; and I am glad to find that, in the new institution to which I have referred, the mistaken views to which I have alluded have been discarded. Houses of this description may be erected which will suggest very little association to the mind of the convalescent with the painful memories of the hospital which he has recently quitted; but, in attaining this most salutary result, we need not thoroughly abandon those principles for which we have contended as essential in the construction of the regular hospital, and which, I believe, cannot be safely disregarded in designing these kindred establishments.

I had originally intended to make some further remarks on the cost of erection of these hospitals. Time, however, forbids me to enter upon it. The strict limit as to the duration of these addresses, which I am commissioned by our executive to enforce, necessitates my careful observance of the rule. I will, therefore, only add that if, by this introductory opening of the subject, I have in any way facilitated its more complete discussion on the day devoted to it, the object I have had in view will have been accomplished.

\section{ADDRESS. IN MEDICINE,}

BY

\author{
SIR WILLIAM JENNER, BART., M.D., F.R.S., \\ Physician in Ordinary to Her Majesty the Queen.
}

Gentlemen,-There are special occasions when it is well for a man to review his mental progress-points in his life at which he does well, nay, is bound, to look back over the road he has travelled; to count his gains, the difficulties he has overcome, the advances he has made; and so be cheered in his present labours, and stimulated to new efforts, gathering from the retrospect good hope for the years to come. The same is true of a profession. Its members should from time to time look back to their earlier days, scan the advances their profession has made, compare what it is now with what it was then, and weigh with unprejudiced eye the worth of its reputed progress.

Advances in practical sciences are not mere changes in ideas or in the modes of expression, which may, as in regard of religion, indicate greater enlightenment of mind; but they are advances in knowledge, the addition to the science of new facts, the elimination of supposed facts, the more correct appreciation of the bearing of old facts, and the application of this new knowledge to the advancement of the practical objects of the science.

There are special reasons why the members of our profession-practitioners of medicine-should from time to time sum up the gains medicine has been making as a practical art. For, in the daily practice of our profession, so much is necessarily met to damp our spirits; so many cases in which diagnosis, in the present state of our art, is altogether impossible, or at the best doubtful; so many in which the practical difficulties in the way of diagnosis, though the art be perfect, are insuperable; so many in which, the diagnosis being clear, we know that we are impotent to cure; so many in regard of which our apparently well founded expectations of effecting a cure prove vain, that even the most hopefully minded must now and then be tempted to doubt if medicine be really advancing as a practical art.

Again, the spirits of many have been damped by the idea that modern advances in the science of medicine have led to scepticism in regard of the remedial powers of medicine as an art, and especially as to the remedial power of drugs. "I trust you will not cast doubts on the efficacy of medicines," said a distinguished member of our profession, speaking to me of this address. "They do not believe much in the worth of drugs at this hospital," wrote a reporter to one of the medical journals. Now, for myself, I desire to absolutely repudiate scepticism in regard of medicine. I believe as confidently in the power of physicians to treat disease successfully as I did when clinical clerk to one of the first practical physicians of my youth. Extended knowledge and accumalated experience have only increased my confidence in the remedial powers of our art. Nor do I believe that others, on whom the imputation of scepticism has been cast, are less firm believers than myself in the value of treatment.

Modern research has shown that a large number of acute diseases occurring in previously sound persons have a tendency to terminate in the restoration of health, even though no drug be given. This is fact -knowledge-not scepticism. Again, modern observation has shown that certain acute diseases, formerly supposed of indefinite duration, run a definite course; i.e., end spontaneously at a certain date from their outset, and therefore that conclusions as to the efficacy of drugs to cut short these diseases-conclusions drawn before their definite duration was known-were founded on false premises, and consequently are not trustworthy. All this is surely fact-knowledge-not scepticism.

Again, advances in knowledge have frequently been attended by a more correct appreciation of the mode of action of drugs; and the expression of this has not unfrequently, though most erroneously, been taken as evidence of scepticism. Thus, if $I$ believe that saline aperients do not act as formerly I supposed they did; viz., by increasing the escape of watery matter from the radicles of the portal vein, I am not in the least shaken in my belief that the symptoms which I attribute to over-distension of the portal vein are relieved by their action, or that their action is followed by the disappearance of watery fluid from the peritoneal cavity and from the cellular tissue.

Again, if it should be considered as proved by experiment on dogs that mercurials do not produce increased secretion of bile in man, it would not in the least throw doubt on the established facts in regard of the great flow of a yellow and green-coloured fluid from the bowel 
after the administration of a mercurial to man, and the relief to many distressing symptoms which follows. A man's bilious headache, as it is termed, would be none the less certainly cured by a mercurial, even though it should be shown to the satisfaction of the whole profession that mercury does not increase the secreting power of the liver. Our modes of explaining certain facts in curative medicine would be changed, but not the facts themselves. My conviction then is, that although with regard to the virtues of this or of that particular drug, and to the mode of action of this or of that particular class of remedies, there is, no doubt, and always will be, difference of opinion-the evidence that satisfies A being insufficient, from the constitution of his mind, to satisfy B. With regard to the value of drugs in the abstract, with regard to the value of treatment, there is really little difference of opinion among physicians equally well informed as to the present state of medical knowledge, and equally experienced in practice. When I say among men equally well informed, let me illustrate my meaning. I was one of three who met in consultation concerning a case of apoplexy. In the opinion of one of my colleagues and myself, the only treatment to be adopted was as follows: to place the patient in the recumbent position, with head and shoulders raised; to enforce absolute rest; to keep the bowels so far loose as to prevent excitement and straining; to apply cooling substances to the head in the event of any heat of the part occurring; to support the patient with light nutritive food, having regard to his habits. The third gentleman protested against the modern system of doing nothing; he was anxious to bleed, to purge, to blister; and, when opposed, was not sparing of the term sceptic, etc. Now, the difference of opinion in this case was not due to scepticism on the one side, and faith-i.e., faith justified by knowledge-on the other; but to knowledge on the one side, and absence of knowledge on the other.

The case was one of degenerative change-retrograde metamorphosis - of the arteries; one had become so rotten that its wall had given way; its contents had escaped; a clot had formed; and, by its mechanical effects, given rise to the symptoms. The heart shared in the degenerative changes; the bleeding had ceased. To those who understood the real nature of the case, the lesions present, and the mode in which they had been produced-in short, the pathology of the casebelief in the efficacy of so-called active treatment appeared to be not merely unjustifiable faith, foundationless faith, faith without knowledge, but to be faith in opposition to knowledge, which in medicine is the worst form of scepticism, inasmuch as it implies doubt of truth and belief in error-doubt which may prevent the saving of life, and belief which, embodied in practice, may kill.

The present appears to me to be one of those special occasions to which I have referred, when with advantage to ourselves we may look back and survey the progress which medicine has made as a practical art in our own time-I mean during the time a large proportion of those here present have been engaged in the study and practice of their profession. The time allotted to this address will not permit me even to enumerate the advances medicine has made during the past twenty-five years ; I shall, therefore, limit myself to pointing out certain great divisions into which some at least of the great practical advances of medicine may be grouped, and to giving as briefly as possible such illustrations of its advances in each of these divisions as seem to me to be sufficient to justify this assertion, viz., that, having regard to the attainment of its practical aims and objects as an art, no science has advanced more during the period in question than has the science of medicine. As an art, I say; for while medicine is universally admitted to have advanced as a science, its progress as a practical art is frequently regarded as trifling and often even denied.

As I do not propose to enumerate all the advances of medicine, so neither is it my intention to refer by name to those by whose labours the great advances in medicine have been made. And with regard to all the illustrations I shall give in confirmation of the position I have taken-in fact, to all advances in medicine as a practical science-it must be remembered that it is rarely, very rarely, if ever, that any great discovery, any great step forward has been the direct result of the labours of a single man. All but invariably it has resulted from the successive labours of many men. And again, it must not be overlooked that, in regard of the advances of medicine as a practical art, the silent workers render most efficient aid ; the results of their unspoken experience confirming or refuting the published assertions of the few. It is to the experience of the mass of the profession that we look for the final establishment of doctrine and of rules of practice.

In the selection I am about to make in confirmation of the statement that our science in its advance as a practical art stands second to none, I am conscious that I shall pass by some facts which others will think of greater value than those I have chosen as illustration; and that others would prefer to illustrate the truth of the position I have taken by reference to more general and abstract principles. But I have been guided in my choice, first, by a desire to avoid disputed facts and theories ; and, secondly, by a consideration of those things which have aided me the most frequently and effectually at the bedside when asking myself those two great questions which are hourly presenting themselves to the mind of the practitioner-What is the illness of the patient ?-What will do him good?

Those points have been to me of the greatest practical service when teaching the student at the bedside. It is clinical teaching that brings most closely home to a physician the importance of every advance in our practical knowledge. By thus limiting myself, I feel that, while this address will more directly attain its object, it will be deficient in novelty and scientific interest; and so as an address, be unworthy of its predecessors. For that I crave your pardon.

Among the really great advances in medicine may be placed the separation of chronic degenerations from diseases. By degenerations I mean-I. Retrograde metamorphosis ; passive changes as distinct from living processes, and especially granular disintegration, fatty degeneration and calcification, rotting and petrifaction; changes which may and do occur in tissues and structures removed from the body, in the bottle of the museum. 2. That change accompanied by thickening and diminution of elasticity which occurs in certain tissues in advancing life. The general diffusion of these degenerations is the characteristic of advancing age. It is, in fact, old age ; so much so that, if a means of preventing these changes should be discovered, that means would be the long sought elixir of life. Rotting petrifaction, and the special change in nutrition to which I have referred, although they occur asso to say-natural changes in advancing life, may occur in the structures of the young, if those structures be damaged by active disease.

As illustration of the clinical importance of these advances in our knowledge, I may refer to the modifications in our opinions and in our practice that have resulted from the application of this general knowledge to the changes that occur in special organs. Thus, our clinical knowledge, in regard of heart-disease, experienced advance with every step in our recognition of these degenerative changes. First, we became acquainted with the fatty metamorphosis of its muscular tissue, i.e., the real conversion by interchange of chemical elementary constituents of the sarcous element of the muscle into olein, etc. - not atrophy proper, any more than is the revolution of a drop of water into hydrogen and oxygen atrophy of the water, but a real decomposition - a decomposition proper to advancing age. Then we learned the relation between this decomposition, rotting or fatty metamorphosis, and impediment to the flow of blood, to the textures of the heart; and we saw that the impediment in many cases was caused by calcification or petrifaction of the coats of the arteries. Subsequently we learned that whatever pathological conditions interfered with the nutrition of the muscular tissue, favoured, to the same degree, this retrograde metamorphosis, rearrangement of chemical constituents, decomposition or rotting, which we call fatty degeneration. So we saw that, mechanically induced congestion of the heart was followed first by increase in muscular tissue and power, and then by such damage to the nutrition of the old and of the newly formed muscular tissue, as to be followed by rotting-i.e, granular disintegration and fatty degeneration; and thus we learned why the hypertrophied heart so often fails after a time to afford its proper physical signs, and to be followed by its consequences.

Again, learning that degeneration of the special structures and tissues occurred simultaneously in particular individuals at about the same time of life, we came to the knowledge of fatty heart and rotten vessels being commonly concomitants; and our general stock of knowledge reached the level of his whose statement, when $I$ heard it made at an early meeting of the Pathological Society, was received with shouts of laughter-viz., that fatty heart is often a preservative lesion. It is so. For the life of an aged person is in greater danger if the walls of his arteries are decayed while his heart retains its full power, than it is if the muscular tissue of the heart is suffering decay in proportion to the loss of resisting power of the arterial walls.

Continuing the illustration from the heart-these advances in pathologico-anatomical knowledge have enabled us clinically to distinguish valvular lesions consequent on endocarditis from those degenerative changes proper to advancing age, and to attach their true significance to those secondary changes which occur in the valves of the heart of the young, the structure of which is damaged by acute inflammation.

We have attained to this practical conclusion; viz., that, regarded from a clinical point of view, structural changes in the valves of the heart are referrible to one of three classes : Imperfection in development ; acute endocarditis ; degenerative changes. And yet further advance of clinical knowledge has shown that non-fatal acute endocarditis is almost limited to acute rheumatism; and that degenerative changes, 
sufficient in degree to interfere with function, do not occur in the valves of the heart till middle lite, and rarely till advancing middle life.

The importance of these facts in enabling us to estimate the clinical value of special valvular murmurs is evident. The influence the acquisition of this knowledge has exerted on practice is well illustrated by reference to a paper in the sixth volume of the Transactions of this Society. In having regard to their clinical significance, the active inflammatory nature of these degenerative lesions of the valves of the heart is regarded as indisputable, and special treatment, in accordance with that opinion, is advocated. Again, the knowledge we have gained of these degenerative changes has enabled us to appreciate at their real worth-to attach to them their true pathological significance, and, by so doing, to influence diagnosis, prognosis, and treatment-those changes in cerebral textures which follow on degeneration of the coats of the arteries and capillaries; to appreciate clinically the importance and signs of those changes in the coats of the larger arteries which, circumscribed and considerable, by the diminution of elasticity and contractility they necessitate, lead to local dilatations-i.e., aneurisms ; and to comprehend why aneurisms of the arteries of the trunk and extremity do not occur spontaneously in childhood or youth, why they are so often the concomitants of early, though advancing, age, and so rarely commence in old age.

A second great advance in medicine has resulted from the knowledge - that elevation of the temperature of the body generally is the only evidence of the existence of pyrexia- of fever in the abstract; that if there be no elevation of temperature, there is no fever; and that the only mode of practically determining the existence of elevation of temperature, and of estimating its degree, is by the use of the thermometer. Although great elevation of temperature may be determined by the hand of the observer, yet there may be very decided elevation of temperature without the hand detecting it. And, certainly, the hand of the ordinary observer gives no correct idea of the degree of elevation. The indexed thermometer ranks in importance with the stethoscope.

I will illustrate the value to us as practitioners of this advance in our knowledge in regard to diagnosis, by reference to its value in the diagnosis of three common diseases.

There is a form of typhoid fever with which we are all familiar, that has been termed latent typhoid fever-a form in which the patient is, from the commencement to the termination of the disease, able to walk about, and even to follow his ordinary occupations. This is a form of the disease in which the patient not very infrequently dies from perforation of his bowel, or from intestinal hæmorrhage, even though, as is usual, the evidence of bowel-irritation has been trifling. The diagnosis of this practically important variety of typhoid fever is often all but im. possible without the use of the thermometer; with its aid, it is comparatively, and it may be absolutely, easy. The thermometer, in this case, enables the practitioner not only to satisfy himself, but also to satisfy the patient and his friends that he is really ill-that he is the subject of fever, and not merely out of sorts, poorly. Accuracy in our diagnosis, in this class of cases, is all important ; for by it we are led to avoid the treatment which some of the symptoms may seem to demand - treatment which, perchance, might lead, as it often has led, to a fatal result ; while, by the ocular demonstration of the existence of the fever which we can give to the patient, we can induce him to take those hygienic precautions so important for his safe passage through the ailment. How often have we all known, in times past, a drastic purge administered by the physician to remove the disordered secretions, and injudicious diet taken by the patient to remove the weakness, lead to
death.

A second illustration of the value of the thermometer as an aid in diagnosis is afforded by cases of acute deposit of tubercle. This is a disease, the diagnosis of which before the use of the thermometer was often impossible. Now, by a consideration of the continuous elevation of temperature-the degree of elevation and the alternations in the degree of elevation - the diagnosis can be made with comparative facility.

A third illustration is aftorded by the aid the thermometer gives in the differential diagnosis of pneumonia and tubercular pneumonia.

So much in illustration of its value to diagnosis; but the thermometer also affords more valuable aid in prognosis : for example, in typhus fever, typhoid fever, pneumonia, and acute rheunatism; and it gives valuable aid in determining the propriety of the treatment pursued in special cases.

A third great advance in our practical knowledge has resulted from the appreciation of the influences of various mechanical consequences of primary diseases.

I may illustrate our advances in this kind of knowledge by the following. When speaking of the distinction which modern clinical medicine draws between inflammatory and degenerative changes in the valves of the heart, I might have referred to the fact that both have a common effect, viz., roughening of the margin of the valves. By this roughened surface fibrine is mechanically separated from the circulating blood-whipped out of it; and to the presence of this fibrine on the valve the greater part of the post mortem visible abnormity is due. Formerly all this fibrine mechanically whipped on to the valve was supposed to be directly exuded as result of endocarditis. Again, portions of this fibrine are frequently detached mechanically, i. e., carried away by the current and arrested here and there in the substance of organs or in the larger vessels leading to or to parts of organs. The rheumatic nephritis figured in Rayer's great work is now known to be capillary embolism; while many cases of paralysis which were not long since altogether in explication are now mátters of every day knowledge to the student, and their relation to embolism, to the washing of portion of fibrine from the valves of the heart, and its arrest in one of the arteries of the brain, is matter of demonstration. Late observations have even rendered it probable that, in a certain proportion of cases at least, that remarkable combination of symptoms to which we give the name aphasia is due to this variety of embolism.

Another illustration of our advance in practical knowledge in this direction, $i . e_{\text {. }}$, of the mechanical origin and consequences of special diseased state, is afforded by a consideration of a cause of death after tracheotomy in diphtheria. The patient, after the opening of the trachea, frequently, as is well known, suffers from disseminated lobular pneumonia; while the trachea may be opened in other conditions without any such result. The lobular pneumonia under the conditions referred to is due to inhalation into the capillary bronchi and air-cells of disintegrated diphtheritic exudation from the larynx, and the mechanical difficulty to its expulsion resulting from the opening into the trachea; and thus mechanically are established numerous centres of diseased action. This knowledge modifies practice most materially, and tends much to the saving of life.

Another class of diseases, in the practical acquaintance with which we have made great progress during the past few years, is that due to fluid blood-poisons; pyæmia, septicæmia, ichorrhæmia, and the allied conditions. In illustration, I may refer to three common diseases, respecting which our advance in knowledge in this direction has a marked influence, not only in enabling us to give an explanation of common secondary affections, but also in regulating treatment.

It is now part of our daily clinical knowledge, that a very large proportion of the fatal cases of typhoid fever are fatal, not from the severity of the original disease-not from the direct secondary consequences of the original disease-but from the effects of absorption of decayed matter from the ulcerated surfaces of the intestine, and the bloodcondition-septicæmia-resulting. From this follow secondary pneumonia, nephritis, hepatitis, etc. The practical conclusion is, that one great point in treatment is to prevent this absorption by the use of remedies calculated to destroy the foetid intestinal contents.

Again, in determining a fatal result in scarlatina, septicæmia often plays a most important part. Absorption from the ulcerated surface of the throat leads to great enlargement of the lymphatic glands about the angle of the jaw, and then to general infection. The same is true in regard of diphtheria. The practical conclusion here is, that one object in treatment is to destroy the absorbing surface (often quite practicable in scarlet fever), and to destroy fotid matters by the use of antiseptics to the pharynx.

Among our advances in the same direction-that is, of the effects of the fluid blood-poisons, and their consequences-should perhaps be classed those great strides forward in practical knowledge which have followed on our study of Bright's disease, its relation to local inflammations, to cerebral hæmorrhage, and to hypertrophy of the left ventricle of the heart. This last addition to our knowledge has advanced cardiac pathology, not only by its direct addition to our stock of knowledge, but also by bringing under general laws some of the apparently most exceptional cases of hypertrophy of the heart.

Another decided advance of modern practical medicine has followed from the greater accuracy and minuteness with which the signs and symptoms of special cases of special diseases have been observed and described, the care with which collections of such cases have been analysed, and the greater precision with which special diseases have in consequence been defined.

Advances of knowledge which have followed are manifested-

I. By the more correct appreciation, in regard of well known diseases, of the relation between objective signs and the lesions found after death. Thus we have attained to a degree of accuracy in the diagnosis of diseases of the heart, lung, brain, spinal cord, etc., which a few years ago would have been regarded as impossible.

2. By the separation of diseases previously confounded as one. E. g., Bright's disease has been proved to include several distinct renal diseases, each requiring its special treatment, and all entitled to the com. 
mon name of Bright's disease only because they have as common consequences lesions resulting from the retention in the blood of urinary elements. To two of these special diseases of the kidney I may refer in illustration ; viz., the gouty and the syphilitic kidney. Again, in recent time we have attained solid grounds for distinguishing pulmonary collapse from pneumonia, gout from rheumatism; and also for separating relapsing, typhus, and typhoid fevers. The advance in our knowledge in regard of the diagnostic symptoms of the last named of these diseases, conjoined to our now knowledge of the symptoms of general acute tuberculisation, and of the origin of the febrile disturbances generally of childhood, has enabled us to separate into its proper constituents the most dissimilar pathological conditions, grouped, in times lately past, under the head infantile remittent fever; and to discard the very name, unless we use it to the public as a cloak for diagnostic ignorance.

3. By the discovery of the existence of diseases formerly unknown. Need I mention Addison's disease, leukæmia, locomotor ataxy, trichinosis, cerebro-spinal meningitis, and albuminoid disease of the various organs? The accurate definition of a new disease is not only a gain in itself, but it enables us to define much more clearly allied diseases. Thus the knowledge of the parasitic nature of a considerable number of the diseases of the skin, not only established the existence of several well-defined genera on a firm basis, but enabled other genera to be more easily and clearly defined-e.g., the precise characters by which tinea tonsurans can be defined, makes tinea decalvans, eczema, and herpes circinnatus, more easily and clearly definable.

The more accurate definition of special diseases has led to a more accurate knowledge of the cause of special diseases-their natural history, if I may say so-a knowledge the importance of which cannot be over estimated. Acute sthenic pneumonia has been shown to have a course almost as definite as the acute specific diseases, and to have an almost certainly favourable termination in youth. The auscuitatory signs of tubercular pneumonia are not to be distinguished from those of ordinary pneumonia; but the former as rarely spares the young as the latter kills them. The diagnosis between these two affections may be made absolutely by their course. The knowledge of the duration and course of diphtheria, the period at which the larynx is likely to become involved, albuminuria to occur, and the nervous phenomena to supervene, has given us great advantages in its treatment.

1 may illustrate the folly of attempting to estimate the value of special treatment of a disease, before the natural history of that disease is known, by the following facts: In $1817-19$, an epidemic of fever prevailed in Edinburgh. This epidemic met with a singularly able historian in Dr. Welche. His object was not to write a history of the epidemic, but to prove the great value of blood-letting in fever. Dr. Welche shows that the mortality from fever in Edinburgh, before the employment of venesection, was very great, the percentage of fatal cases very considerable; and he proves indisputably that, after the introduction of free bloodletting, the mortality was comparatively, nay, absolutely, trifling. So frequently did the fever cease after the blood-letting, so quickly did the cessation of the fever follow on the venesection, that to the man who employed the lancet boldly in the treatment of fever, Dr. Welche thought it might be said, "O homo! jugulasti febrem." Now the investigations of the physicians of the past twenty-five years have proved that the disease which Dr. Welche supposed he had killed by bloodletting, was a disease which runs a short and definite course, ends spontaneously on or about the date at which he thought he killed it by blood-letting, and terminates almost always in health under all treatment and without treatment. It is wonderful to observe how few died, though, in the hope of killing the fever, 120 to 130 ounces of blood were taken from the arm in a few days in several cases.

Another great advance in practical medicine is the recognition of the frequent relation of local lesions to chronic constitutional states. No practitioner would now think of treating a local disease till the diagnosis of the constitutional state had been made. For example, in bronchitis in a child, both the prognosis and the treatment will be greatly modified by the fact that the little one is the subject of tuberculosis, of strumosis, of rickets, or of constitutional syphilis. In Bright's disease, both prognosis and treatment will be modified by the fact of the patient being the subject of constitutional gout, of tuberculosis, or of syphilis.

So in regard of intracranial diseases-I may instance meningitis, tumour, disease of arteries, interfering with nutrition as local diseases, for the successful treatment of which it is now admitted that a knowledge of the constitutional state is in every case essential. Surely this is a great stride in practical medicine.

The increased accuracy of late attained in the definition of special diseases, and of their course, has been greatly assisted by the use of special instruments for the detection of physical changes previously imperfectly recognisable. Without the microscope, the existence of leukæmia could not have been established; to its aid is due the knowledge of the parasitic characters of tinea tonsurans, tinea favosa, chloasma, and thrush ; it has yielded indisputable evidence of progressing destruction of lung-tissue ; to it we are indebted for the separation of hydatid cysts from the various forms of simple cysts with which they were so long confounded, as well as for a knowledge of the real nature of the former. The diagnosis, prognosis, and treatment of Bright's disease are all aided by the information the microscope conveys.

The thermometer, to the clinical physician, affords, as we have already seen, information of the highest practical value, whether regard be had to diagnosis, to prognosis, or to treatment.

The laryngoscope has enabled us to appreciate changes in the larynx which, without its aid, could not have been suspected; and to determine with certainty the presence of other lesions which without it could only have been suspected-e.g., growths within the larynx, paralysis of one or both vocal cords, small ulcers on the cords ; and in two of these affections to detect the disease with certainty is to be able, with equal certainty, to cure the patient.

The ophthalmoscope has afforded valuable definite information in aid of the diagnosis of some of the most obscure diseases of the brain and its membranes.

The sphygmograph has accomplished something for medicine as a science and an art, and promises much more.

The balance is an instrument of great importance, as determining the progress - that is, the advance or otherwise-of certain important diseases; and so the value of the treatment being pursucd ; e.g., diabetes and phthisis.

Another great gain to modern medicine has resulted from the diffusion of more correct ideas as to the meaning of the word cure, and of the distinction to be drawn between curing the disease and curing the patient.

The meanings of the word cure are best illustrated by reference to some special diseases. We cure scabies. It is to be observed, however, that when we cure scabies we do not cure the visible symptoms of the disease; but we destroy the agent the presence of which calls forth the visible symptoms. That agent being destroyed, nature cures the inflammation, vesication, pustulation, etc. We do what the surgeon does when he removes a thorn. He does not cure the inflammation excited by the thorn, but he removes that which keeps up the inflammation, and then Nature cures the inflammation.

Ague is, again, a disease of another kind, which we remove, that is, cure, by the use of certain drugs. The ague fit, once established, is not curable-i.e., it runs its course ; and then we prevent the recurrence of the ague fit. We cure or remove the condition which leads to the recurrence of the fit, over the symptoms and duration of which we exercise no control. We cure the disease.

Epilepsy is another disease which we cure. Each fit, like the attack of ague, once begun, runs its course uncontrolled. Epilepsy is sometimes occasioned by a special exciting cause, an irritant present at some one point - the thorn, so to say. For example, a man suffered from epilepsy. He passed joints of tapeworm; the worm was removed, and the fits did not recur. Years afterwards, the epilepsy recurred ; and he said, "Oh, I must have another tapeworm." A dose of male-fern did remove another tapeworm; and again the fits ceased. Now, we may say the epilepsy was cured by the removal of the tapeworm; but it is to be noted that, although the excitant of the attacks was removed, the disease of the nervous system was untouched, as was shown by the recurrence of the manifestation of the disease as soon as the special irritant was again applied. Again, we cure epilepsy, we say, when, by the administration of drugs, we so modify the nervous system that, on the application of the irritants which previously induced a fit, no attack follows.

We cure patients suffering from the acute specific diseases. An acute specific fever is analogous not to ague generally, but to a single fit of ague; and as we have no drug that controls the duration of the fit, so we have no drug that controls the course or duration of the acute specific fevers. We have no drug to cut short the fever-no drug that exercises, so far as is known, any influence on the specific disease. But, notwithstanding this, there is probably no class of diseases in which we more frequently cure the patient; that is, by our knowledge of the course of these diseases, of the dangers which threaten the life of the patient at each stage; and by the judicious employment of remedies, under which are to be included air, food, stimulants, and drugs, commonly so-called-directly, positively, prevent the patient from dying. The treatment is not expectant; it is positive, and even often anticipatory. We do not stand by and let the disease run its course unmodified. We interfere at every stage, to prevent, control, or counteract the consequences of the disease. We restrain diarrhœea; we check hiemorrhage; we prevent septicæmia ; and regulate, by giving or withholding stimu- 
lants and food, the powers of the patient. We cure, but how we know not, a patient suffering from local nerve-pain; we cut short the pain by the administration of drugs, concerning the mode of action of which we know nothing. We cure the most distressing sufferings of constitutional syphilis by the administration of drugs, concerning the modus operandi of which we are really ignorant. The distinction between curing the disease and curing the patient is real.

Though the science of medicine had attained to such degree of perfection that the diagnosis of special diseases was perfect, and the prognosis in individual cases invariably correct, the public would have little practical interest in its spread. Its practitioners would be engaged in solving puzzles, and in little more. So far as concerns the non-professional public, the aims and objects of medicine ought to be-

To prevent disease ;

To cure disease;

To prolong life ; and

To alleviate physical suffering.

But then it is manifest that the definition of special diseases must precede all attempts to determine their several causes and their modes of cure. Every advance, therefore, in the correct definition of special diseases, and in the diagnosis of special diseases, is a step in the direction of an advance of preventive and of curative medicine.

In illustration of the advances made in preventive medicine, I will adduce the firm establishment of the fact that drinking water is one of the greatest agents in the spread of two of the most fatal acute diseases of the present time; viz., cholera and typhoid fever. In the ten years ending 1866, 21,848 persons died from cholera in England and Wales; and 192,562 from fever. From the Registrar-General's returns, it is not possible to say precisely how many of the 192,562 persons died from typhoid fever; but, seeing that typhoid fever is the endemic fever of our country, and that typhus prevails as an epidemic only, and that in limited localities and for a short time, we shall be within the limits of high probability when we say that 150,000 persons died of typhoid fever during the ten years in question, and that in no one year of the ten did less than 10,000 persons die of that disease. Now, with reference to cholera, the special facts collected by Dr. Snow proved that one of the great agents in the diffusion of cholera was drinking water; that every virulent local outbreak in a limited district of the disease was clearly coincident with pollution of the drinking water supplied to that district ; and that persons living at a distance, if by accident they drank of the polluted water, suffered as certainly as if they dwelt in the district specially affected. The conclusion which follows from the facts collected by Dr. Snow is that, the conditions existing, be they atmospheric or other, which determine the epidemic disposition to cholera, the presence of minute portions of cholera excreta in the water supplied to a district for drinking purposes, will be followed by an outbreak of cholera in that district. Careful investigations into the circumstances attending local virulent outbursts of cholera during the last epidemic, have proved the truth of that conclusion. I will refer to two such special investigations in confirmation, viz., Mr. Radcliffe's admirable researches into the relation between the water-supply and the spread of cholera in London; and to Dr. Bellot's most conclusive observations on impure water as a cause of cholera in Holland. Dr. Snow's investigations traced special individual cases and local outbreaks to one exciting cause. Mr. Radcliffe's researches bear especially on the influence of the polluted water in determining excess of mortality in a large district of a great city. Dr. Bellot's facts show that those towns and those parts of a town in Holland in which there was the greatest facility for the contamination of the water-supply by cholera dejections were those which suffered by far the most severely.

The spread of typhoid fever by contamination of the drinking-water supply is, if possible, less disputable than is the spread of cholera by the same means. Every new investigation has added new proofs to the strong presumptive evidence afforded by Dr. Flint's cases. Solitary cases, outbreaks confined to single houses, to small villages, and to parts of large towns-cases isolated, it seems, from all sources of fallacy -and epidemics affecting the inhabitants of large though limited local ities, have all united to support by their testimony the truth of the opinion that the admixture of a trace of focal matter, but especially of the bowel-excreta of typhoid fever with the water supplied for drinking purposes, is the most efficient cause of the spread of the disease; and that thediffusion of the disease in any given locality is limited or otherwise just in proportion as the dwellers in that locality derive their supply of drinking water from polluted or from unpolluted sources. The proof seems complete, that a large proportion of those who drink water containing a minute quantity of the intestinal excreta from a person suffering from cholera will suffer cholera; and that a large proportion of those who drink water containing a minute quantity of the intestinal excreta from a person suffering from typhoid fever will suffer typhoid fever. These diseases occur like small-pox, scarlet fever, and measles, as epidemics, owing to causes of which we know little or nothing; but, when epidemic,- - unlike small-pox, scarlet fever, and measles, - a local outbreak of cholera and of typhoid fever will be determined by the impurity of the drinking water. Had the water supplied to the east of London been as free from organic impurity as was that supplied to the west of London, the death-rate from cholera at the east would have been a little larger only than was the death-rate at the west of London. Had the drainage and water-supply of Winterton, Terling and Guildford, been what modern medicine has shown for health purposes they should have been, these places would not have suffered the terrible outbreaks of typhoid fever of which the medical officer of the Privy Council gives such full details in the tenth volume of his inexpressibly valuable reports. The persons who died at these places from typhoid fever, and a large proportion of those who died at the east of London from cholera, were as certainly killed by the water they drank, and killed without need, as if the water supplied to them had been contaminated with arsenic.

And I am sure we all agree with the most distinguished medical officer of the Privy Council, that "the distribution of fouled water by the Guildford Board, is as proper a case for judge and jury on action for damages by any of the five hundred people who had typhoid fever in that town, as any case in which a railway collision brings some score of passengers into harm; and the fact that these water-purveyors gave typhoid fever to their customers, would be brought home to their consciences, and be suggested as a warning to other water-purveyors, in a far more conclusive and effective manner by such legal proceedings than it can be by any departmental statistics and remonstrances."

Another advance in preventive medicine, second only in importance (even if it be second) to those just mentioned, has resulted from the knowledge, lately acquired, of the influence of dampness of soil in the production of phthisis. Dr. Bowditch's and Dr. Buchanan's independent researches have placed beyond question the relation between dampness of soil and phthisis, and have proved that drying of the soil by proper drainage of any given locality is followed by remarkable diminution in that locality of the death-rate from phthisis. By im. proved drainage, causing dryness of the soil, in Rugby, the phthisis mortality has fallen 43; in Salisbury, 49; and in Ely, 47 per cent.

Thus, by the advances of modern medicine, the public have gained certain knowledge of the means of preventing, to a very great extent, the spread of two of the most fatal of acute diseases, and of preventing the occurrence, in a large number of cases, of the most fatal of chronic ailments.

The advances of curative medicine have been as decided as those of preventive medicine. Not only have sounder views of the rational treatment of special diseases, based on advances of pathological knowledge, been established, but new drugs, of great practical worth, have been introduced into our pharmacopœia, and old drugs have been found to possess virtues heretofore unsuspected. How wonderful is the influence of bromide of potassium over diseases, for the treatment of which we were but a few years since almost impotent! A dull, heavy-looking lad suffered, for seven years, from epileptic attacks, steadily increased from the first in severity and frequency, till many occurred in the twentyfour hours. For a year he was treated by a physician, on general principles, with little benefit. The case was in all particulars most unpromising ; yet, from the time the boy took the first dose of bromide of potassium to the present, nearly three years, he has not had a single fit.

Is this a solitary case? Certainly not. We could all match it. But it illustrates well the power of a new drug over a class of cases which, not long ago, were regarded by practical men as almost as much beyond the curative influence of drugs as is a case of cancer of the breast. To one other of the powers of this drug I must advert; viz., its influence on the sexual organs, - a power which enables us to exercise a real curative influence over a class of most distressing affections for which, by drugs at least, we could formerly do nothing.

Other illustrations of the strides made in drug-therapeutics, are afforded by the influence of cod-liver oil on the cachexia of tubercular disease and of rickets; of iron on the cachexia of the aged; of digitalis as a cardiac tonic; of ipecacuanha in the cure of dysentery; of sulphites and sulphurous acid, and of carbolic acid, in the treatment of vegetable parasites; and of Faradisation and the continuous current in some morbid states of the nervous system.

The progress of pathological knowledge has been followed by an equal advance in the rational treatment of disease. Means were formerly sought to strangle a fever, to cut short a pneumonia. Increase of knowledge has taught us that these diseases always terminate within a limited period, but are never cut short; while collections of facts have proved what, in the present state of pathological and physiological 
knowledge, might have been predicated; viz., that a larger proportion of these diseases terminate in health under restorative treatment than under depleting remedies. The propriety of the substitution of food and moderate quantities of stimulants, as routine practice, for the lancet, rests on the firm basis of results; and this firm basis is established without regard to the answer that may be given by science to the question, Is alcohol food or heart-stimulant, or a nerve-power supporter?

But, while admitting this general conclusion, the profession as a whole have not forgotten that there is no one treatment applicable to all cases of disease bearing the same name. They have not failed to see that the practitioner is distinguished from the routinist by his ability to discern when, with advantage to the patient, he may deviate from rules of practice generally applicable. No tables, however carefully compiled, however ably analysed, can teach a man how to treat the case of fever, or the case of pneumonia, now under his care.

A good illustration of the help yielded to us in the rational treatment of a special disease, from advances in our pathological knowledge in regard of that disease, is afforded by chronic pulmonary vesicular emphysema.

The diminution of the elasticity of the lung can, in many cases, be retarded; the exciting and determining causes of over-distension of the air-vesicles can be shunned; the causes of temporary impediments to the flow of blood through the pulmonary capillaries can be avoided ; congestion of the heart, liver, kidneys, etc., can in this way be lessened, and, by direct remedies, still further diminished or removed. And thus sufferings are alleviated,-serious secondary lesions of structure in organs, the integrity of which is essential to life, in a great measure prevented, and life itself indefinitely prolonged.

The benefit derived from opening the trachea in croup, is another illustration of the value of rational treatment in the prolongation of life.

With reference to the power of our art to alleviate suffering, how great is the difference between the medicine of to-day and that of our youth! Who that has suffered from a painful local affection can think of the alleviation to his sufferings which followed on the subcutaneous injection of an anodyne, without gratitude? Who is there that has had to submit to the knife of the surgeon, whose heart does not overflow with gratitude to those who introduced and perfected local and general anæsthesia? The electric telegraph, the second greatest marvel of our time, was a thing which, in a rough way, scientific men had long thought possible; but to be cut for stone, and know nothing of the agony; to have a leg removed, and smilingly ask, when the operation is over, "When are you going to begin?" to have a toe-nail torn away, and look on and laugh when that most painful operation is proceeding, - these are marvels of which none dreamed. No extravagance of fiction equals this reality. The discovery of the value of the subcutaneous injection of anodynes, of local anæsthesia by ice and ether-spray, and of general anæsthesia by ether, chloroform, and nitrous oxide, are advances in alleviative medicine worthy to rank with the advances in preventive, curative, and prolongative medicine to which $I$ have referred.

Keeping in view, then, those practical aims and objects for which medicine is esteemed by the public-viz., its power to prevent disease, to cure disease, to prolong life, to alleviate suffering-I feel that I have said enough amply to prove the truth of my assertion that the progress of medicine as an art has during the past twenty-five years* been second to that of no other science. And the present advanced state of medical education; the perfection of the means of physical research; the many new centres of knowledge being established in our colonial empire and in America; the widely diffused acquaintance of the profession with modern languages; the rapidity with which knowledge spreads; the confirmation, correction, or refutation which follows so quickly on the publication of novelties; the great ability; the absence of prejudice; the untiring energy; and the truthfulness exhibited by the younger workers in the field of our science,-render me hopeful that the next quarter of a century will be distinguished by far greater progress than has the last, great though that be. And I can even now in mind realise the day when most of us, our faculties numbed by age, shall take but listless interest in the then present-or be, as is perhaps to be hoped, where suffering has no place, - and when another, as full of sympathy for physical suffering, as anxious to relieve it, as we are now, shall stand in this place and tell how, twenty-five years before, one stood here and with exulting voice spoke of the advances of medicine in the preceding quarter of a century; but only to add that the sum of those boasted advances was but as nothing, compared to the strides the profession had made as a practical art since that far-away day.

* Too narrow a limit must not be given to the twenty-five years, as the writer intended rather to fix a time within which the illustrations given had become part of the stock knowledge of the profession, than fix with accuracy dates when each fact was published by its discoverer.

\section{ON THE DETECTION AND TREATMENT OF FOREIGN BODIES IN THE BLADDER: WITH REMARKS ON THE USE OF THE ENDOSCOPE.*}

\author{
By EDWARD LUND, F.R.C.S.
}

THE endoscope, as we now use it, is an instrument of modern improvement. In its present form, it is the invention of Dr. Cruise of Dublin; but, long before he succeeded in bringing it to perfection, many other observers, and especially the late Mr. Avery, had attempted the same thing by very similar arrangements. To be able to view, with exactitude and precision, the interior cavities of the body, must be in some cases of great importance; yet the very limited range of vision thus obtainable will ever keep this instrument as one to be employed more as an aid to other methods of diagnosis, than for constant use. There are many little details of management in Dr. Cruise's endoscope which need not here be referred to; but among these I may especially mention the fact, as he has stated it, that we can obtain a greater illuminating power from the flame of a lamp when its thin edge is placed towards the mirror, than by using its broad surface; and also that no fluid is so useful for combustion, and gives so good a light, as pure petroleum, in which about ten grains of camphor have been dissolved in each fluidounce.

There is one source of difficulty in using this instrument which may cause much annoyance. It is that, in order to see an object with the endoscope, in the bladder filled with urine or water which has been injected into it, it is necessary that the window of the endoscope-tube should be brought into very near contact with the body to be examined; indeed, the tube should first be used as a sound or searcher to find the foreign substance; and then, having got some clue to its exact position in the bladder, we may hope to have it properly illuminated. If this is not done, the water by which the window of the tube is surrounded absorbs the light so completely that, to use Dr. Cruise's own words in a letter to me on this subject, "you can see nothing but darkness until the window of the speculum touches some object, such as the mucous membrane, a stone, or the like." This property of water to absorb the rays of light is well known to opticians; for it is said that, during the operation of diving in deep water, at a certain distance below the surface, all the light from above is cut off, and darkness prevails; and this same condition may exist in diving about in the bladder with the endoscope-tube, seeking to discover some foreign body, when, if it happen to be of a dark colour, we may imagine that we are really viewing it, while all the time the black colour produced is the result of the light being shed out into the mass of water through the window of the speculum-tube.

T. W. H., aged 17 years, was admitted into the Manchester Royal Infirmary, under my care, on August 28th, I868. He was an intelligent, well-educated boy, of rather reserved taciturn disposition ; and all I could ascertain in reference to the case was that, about four days previously in the evening, while in a dark room, he had passed a piece of India-rubber tubing, such as is used for infants' feeding-bottles, along his urethra; the penis becoming suddenly erected, the tubing slipped into the bladder, and he could not recover it. He did not have any pain ; and it was not until two days afterwards, when he could not pass urine, and was suffering great distress from the distension of the bladder, that a surgeon was sent for, and he confessed to him what he had done. A catheter was used. It could not be passed quite into the bladder, for it seemed as if the urethra was blocked up by some foreign body; but, on withdrawing the instrument, the urine flowed off, with occasional interruptions, until the bladder was emptied; and after this he had no further difficulty in the passage of the urine. The boy stated that the piece of tubing was about six inches in length, and of the diameter of a common writing-quill.

On August 29th, I examined him with the endoscope while lying on his back in bed. I did not give him chloroform, and he bore the examination very well. I could see a dark mass in the bladder on his left side, with a sharp outline or edge; while all the other parts of the interior, where the mucous membrane could be seen, were of a pinkish salmon colour. This I thought must be the foreign body which I sought for, coiled up in some way so as not to give the outline or exact form of a tube; yet this was very doubtful. The urine was clear, acid, free from mucus or other deposit. The patient did not suffer any pain, except a vague general feeling of weight or uneasiness in the region of the bladder just above the pubes, neither relieved nor increased by pressure.

* Being the substance of a paper read before the Medical Section of the Manchester Royal Institution on April 7 th, 1869. 